\title{
ANALISIS TINGKAT KESEHATAN PT. BANK RAKYAT INDONESIA (BRI) SYARIAH BERDASARKAN METODE RGEC
}

\author{
Muhamad Manarul Hidayat \\ Manajemen Keuangan Syariah, UIN Sunan Gunung Djati Bandung \\ muhamadmanarulhidayat4@gmail.com \\ Usep Deden Suherman \\ Manajemen Keuangan Syariah, UIN Sunan Gunung Djati Bandung \\ usepdedensuherman@uinsgd.ac.id \\ Hendra Safri \\ Perbankan Syariah Institut Agama Islam Negeri Palopo, Makasar \\ jaka_jajuli@yahoo.com
}

\begin{abstract}
Every bank must have a bank soundness level from all aspects with very healthy criteria, as well as PT. BRI Syariah. Therefore, this article aims to analyze the factors that affect the health level of PT. BRI Syariah uses Bank Indonesia regulations, namely PBI No.13 / 1 / PBI / 2011 and criteria guidelines for using SE. No.13 / 24 / DPNP. In accordance with these provisions, the soundness of a bank is measured by the RGEC method (Risk Profile, Good Corporate Governance, Earnings, and Capital). This article uses descriptive methods and quantitative approaches to determine the health level of PT. BRI Syariah is also compared to two state-owned sharia banks, namely PT. BNI Syariah and BSM. The results showed that using the RGEC method the assessment factors used were NPF, FDR, ROA, BOPO, CAR, and ROE. It appears that PT. The health level of BRI Syariah is still below BNI Syariah and BSM. This indicates that BRI Syariah still has to improve its financial performance to have a healthy rating at rank one, which is very bealthy.
\end{abstract}

Keywords: Health Level, RGEC Method, BRI Syariah

\begin{abstract}
Abstrak
Setiap bank harus memiliki tingkat kesehatan bank dari segala aspek dengan kriteria sangat sehat, begitupula dengan PT. BRI Syariah. Maka dari itu, artikel ini bertujuan menganalisis faktor-faktor yang mempengaruhi tingkat kesehatan PT. BRI Syariah menggunakan ketentuan Bank Indonesia yaitu PBI No.13/1/PBI/2011 dan pedoman kriteria menggunakan SE. No.13/24/DPNP. Sesuai ketentuan tersebut, tingkat kesehatan bank diukur dengan metode RGEC (Risk Profile, Good Corporate Governance, Earnings, and Capital). Artikel ini menggunakan metode deskriptif dan pendekatan kuantitatif untuk mengetahui tingkat kesehatan PT. BRI Syariah yang mana juga dibandingkan dengan dua bank syariah milik BUMN yaitu PT. BNI Syariah dan BSM. Hasil penelitian menunjukkan bahwa dengan menggunakan metode RGEC faktor penilaian yang digunakan adalah NPF, FDR, ROA, BOPO, CAR, dan ROE. Terlihat bahwa Tingkat kesehatan PT. BRI Syariah masih berada di bawah BNI Syariah dan BSM. Hal ini menandakan bahwa BRI Syariah masih harus meningkatkan kinerja keuangannya untuk memiliki peringkat yang sehat pada peringkat satu yaitu sangat sehat.
\end{abstract}

Kata kunci: Tingkat Kesehatan, Metode RGEC, BRI Syariah 


\section{Pendahuluan}

Penelitian ini dilatarbelakangi oleh bencana pandemi Covid-19 yang mengguncang perekonomian dunia, tak terkecuali perekonomian Indonesia. Sebagai negara yang berkembang, ketidakstabilan ekonomi akan mempengaruhi segala sektor, termasuk sektor perbankan. Maksudnya disini adalah, ketidakstabilan ini akan mempengaruhi nasabah dan kondisi finansial bank itu sendiri.

Jika merujuk pada kilas balik bank syariah, Indonesia baru memiliki 14 bank umum syariah hingga tahun 2020 ini. Dari 14 bank tersebut, bank umum syariah milik BUMN hanya tiga bank saja. Pangsa pasar bank umum syariah sendiri secara keseluruhan masih terbilang kecil jika dibandingkan dengan pangsa pasar secara umum. Maka dengan keadaan pandemi seperti ini, pasti akan mempengaruhi kondisi kesehatan bank syariah.

Namun peneliti akan melakukan penelitian evaluasi terhadap kesehatan bank umum syariah milik BUMN khususnya PT. BRI Syariah sejak 2018 hingga 2019. Dengan data tingkat kesehatan ini, masyarakat akan mengetahui apakah kondisi kesehatan BRI Syariah baik-baik saja sebelum pandemi, dan mampu bertahan di era pandemi Covid-19 ini. Data pembanding akan ditampilkan yaitu bank umum syariah milik BUMN lainnya, sehingga akan terlihat bank umum syariah milik BUMN yang mana yang kondisi kesehatan banknya stabil dari segi rasio keuangannya.

PT. BRI Syariah menjadi bank umum syariah sejak 17 November 2008, dengan jalan spin off unit usaha syariah BRI dan konversi perbankan milik swasta yaitu PT. Bank Jasa Arta pada 19 Desember 2007. Sebagai unit usaha syariah dari PT. Bank Rakyat Indonesia milik BUMN yang terbilang memiliki pangsa pasar yang luas, BRI Syariah belum mampu menyamai induk usahanya dahulu. Karena jika dibandingkan dari segi umur berdiri masih jauh, dan pemilik pangsa pasar bank syariah terbesar saat ini dikuasai oleh PT. Bank Syariah Mandiri.

Berdasar pada asumsi di atas, peneliti akan melakukan penelitian mengenai tingkat kesehatan PT. BRI Syariah periode 2018-2019. Kesehatan bank diartikan sebagai kemampuan perbankan dalam memenuhi seluruh kewajiban dan menjalankan kegiatan operasionalnya (Umam, 2013). Sementara itu, tingkat kesehatan bank berarti hasil evaluasi objektif atas keadaan sebenarnya bank yang dilihat pada laporan keuangan bank itu sendiri. Tingkat kesehatan bank sendiri digunakan sebagai alat evaluasi kebijakan dan merumuskan kebijakan pengelolaan bank ke depannya.

Bank Indonesia sebelum nya menetapkan suatu metode CAMELS dalam menilai tingkat kesehatan suatu bank bank. Aturan tersebut sinkron dengan Aturan Bank Indonesia pada Nomor: 6/10/PBI/2004 untuk nilai kesehatan bank dilakukan berdasarkan penilaian kualitatif dan kuantitatif berdasarkan faktor-faktor yang memiliki pengaruh untuk kinerja bank, seperti kualitas aset (asset quality), modal (capita), rentabilitas (earnings), manajemen (management), kepekaan pada pasar risiko (sensitivity to market risk) dan likuiditas (liquidity). Profil dan manajemen risiko pasar yang dipublikasikan bank sebagai penilaian kualitatif. Menurut Permana (2012), pengukuran tingkat kesehatan pada bank melalui metode CAMELS tidak efektif karena hanya menyimpulkan suatu penilaian yang bersifat berbeda

Mengacu pada Peraturan Bank Indonesia (PBI) No.13/1/PBI/2011, metode RGEC resmi menggantikan metode CAMELS sebagai alat analisis tingkat kesehatan bank. Kemudian turunan dari PBI tersebut adalah SE. No. 13/24/DPNP/2011 di dalamnya diwajibkan agar dapat melakukan penilaian bank (self assesment) tingkat sehatnya pada bank oleh rancangan risiko (Risk-based Bank Rating/ RBBR) dengan sendiri ataupun konsolidsi. Metode RGEC merupakan 
singkatan dari risk, profile, good corporater governance, earnings, dan capital yang merupakan faktorfaktor penilaian dari metode tersebut.

Peraturan ini harus diterapkan untuk bank yang bekerja di Indonesia. Bank dinyatakan sehat bila bank tersebut mampu menjalankan fungsi ataupun aktivitasnya dengan lancar. Menurut Dwinanda dan Wiagustini (2014), kualitas dari kinerja manajemen bank ditekankan pada metode RGEC. Lalu dapat mengunakan langkah perbaikan agar berkurangnya risiko dan terhindar dari kegagalan bank ini lebih jauh lagi agar mencegah terjadi suatu krisis keuangan di dalam sistem ekonomi Indonesia (Budiman et al., 2017).

Berdasarkan paparan di atas, penelitian berfokus pada penilaian tingkat kesehatan PT. BRI Syariah menggunakan metode RGEC yang diproksikan menggunakan Non Performing Financing (NPF), Financing to Deposit Ratio (FDR), Return On Assets (ROA), Beban Operasional terhadap Pendapatan Operasional (BOPO), dan Capital Adequancy Ratio (CAR).

\section{Metode}

Artikel ini juga menggunakan metode deskriptif-analitis dan pendekatan kuantitatif. Metode tersebut untuk mendeskripsikan hasil penelitian yang datanya disajikan dalam bentuk numerik (Sugiyono, 2013). Data tersebut adalah penghitungan rasio-rasio keuangan yang mengacu pada Peraturan Bank Indonesia (PBI) No.13/1/PBI/2011 tentang Analisis Tingkat Kesehatan Bank Syariah. Data pada artikel ini merupakan data sekunder yang diambil dari laporan keuangan Bank Umum Syariah Milik BUMN dan didukung dengan studi kepustakaan dan dokumentasi. Teknik analisis data pada penelitian menggunakan analisis deskriptif. Cara ini digunakan untuk melihat kinerja masa lalu agar dapat mengambil kesimpulan. Tujuan dari metode penelitian ini adalah untuk mendekskripsikan dan mengidentifikasi tingkat kesehatan PT. BRI Syariah sesuai dengan ketentuan Bank Indonesia.

\section{Hasil Penelitian dan Pembahasan}

Penelitian ini menganalisis peringkat kesehatan bank umum syariah milik BUMN yaitu PT. Bank Rakyat Indonesia (BRI) Syariah menggunakan metode RGEC dan membandingkannya dengan Bank Umum Syariah Milik BUMN yang lainnya.

\subsection{Analisis Peringkat Kesehatan Non Performing Financing (NPF)}

Non Performing Financing (NPF) ialah komponen dari risk profile, yang menunjukkan persentase pembiayaan bermasalah pada suatu bank. Artinya nasabah memiliki ketidakmampuan dalam menepati perjanjian yang telah disetujui oleh bank dan nasabah di mana secara teknis dikenal dengan sebutan default (Rivai \& Ismail, 2013). Bagi perbankan NPF mendeskripsikan bagaimana pihak bank mengelola pembiayaan yang default, sehingga ketika rasionya semakin besar menunjukkan buruknya kualitas pembiayaan bank tersebut dan berdampak pada kemungkinan bermasalahnya sutatu bank semakin besar. Selain itu pembiayaan bermasalah yang mengandung kemacetan pelunasan berpengaruh terhadap peringkat kesehatan bank (Umam, 2013).

Berdasarkan Surat Edaran Bank Indonesia tingkat kesehatan Non Performing Financing (NPF) suatu bank diukur dari matriks kriteria penetapan peringkat NPF, yaitu sebagai berikut:

\begin{tabular}{|c|c|c|}
\multicolumn{2}{c|}{ Tabel 1 Matriks Kriteria Penetapan Peringkat NPF } \\
\hline Peringkat & Tingkat keadaan & Kriteria \\
\hline 1 & Sangat Sehat & NPF $<2 \%$ \\
\hline 2 & Sehat & $2 \% \leq \mathrm{NPF}<5 \%$ \\
\hline
\end{tabular}




\begin{tabular}{|c|c|c|}
\hline 3 & Cukup sehat & $5 \% \leq \mathrm{NPF}<8 \%$ \\
\hline 4 & Kurang Sehat & $8 \% \leq \mathrm{NPF}<12 \%$ \\
\hline 5 & Tidak Sehat & $\mathrm{NPF} \geq 12 \%$ \\
\hline
\end{tabular}

Sumber: Surat Edaran Bank Indonesia

Adapun data kondisi NPF Bank Umum Syariah milik BUMN pada tahun 2018-2019 dapat dilihat pada tabel berikut:

Tabel 2 Kondisi Non Performing Financing (NPF)

\begin{tabular}{|c|l|c|c|c|c|}
\hline No & \multicolumn{1}{|c|}{ Nama Bank } & $\mathbf{2 0 1 8}$ & Nilai & $\mathbf{2 0 1 9}$ & Nilai \\
\hline 1 & PT. BRI Syariah & $4,97 \%$ & Sehat & $3,38 \%$ & Sehat \\
\hline 2 & PT. BNI Syariah & $1,52 \%$ & Sangat Sehat & $1,44 \%$ & Sangat Sehat \\
\hline 3 & PT. BSM & $1,56 \%$ & Sangat Sehat & $1,00 \%$ & Sangat Sehat \\
\hline
\end{tabular}

Sumber: Annual Report PT. BRI Syariah, PT. BNI Syariah, dan PT. BSM 2019

Berdasarkan data di atas Bank BRI Syariah pada tahun 2018 dan tahun 2019 menunjukan Rasio NPF dari tahun 2018 ke 2019 mengalami penurunan. NPF tahun 2018 adalah 4,97\% mengalami penurunan sebesar 1,59\% menjadi 3,38\%. Kemudian PT. BNI Syariah menunjukkan rasio NPF sangat sehat selama dua tahun berturut-turut, dengan persentase 1,52\% turun sebesar 0,08\% sehingga tahun 2019 menjadi 1,44\%. Dan PT. BSM memiliki NPF yang juga sangat sehat, hal ini ditunjukkan dengan persentase yang turun dari 2018 sebesar $1,56 \%$ menjadi $1,00 \%$ pada tahun 2019. Nilai rasio NPF diatas menunjukan bahwa bank umum syariah miliki BUMN memiliki rasio pembiayaan yang bermasalah rendah dan tingkat kesehatan banknya masih sangat sehat dan sehat. Namun jika dilihat diantara ketiganya, PT. BRI Syariah memiliki nilai NPF yang tinggi, sehingga menurut hemat peneliti PT. BRI Syariah masih harus memperbaiki manajemen pengelolaan nasabah dengan pembiayaan bermasalah. Seperti, melakukun uji kelayakan nasabah dengan baik, memonitoring usaha nasabah seperti UMKM yang diberikan pembiayaan secara intens, sehingga NPF juga berada pada peringkat sangat sehat.

\subsection{Analisis Tingkat Kesehatan Financing to Deposit Ratio (FDR)}

Financing to Deposit Ratio (FDR) merupakan pengukuran kesehatan bank melalui rasio likuiditas yang masih menjadi komponen risk profile. Menurut Muhammad dalam Pratiwi (2012) FDR menggunakan ketersediaan dana yang ada pada bank dana pihak pertama, kedua, dan ketiga untuk menggambarkan kesanggupan bank memenuhi permintaan dari nasabah dalam hal pembiayaan (Pratiwi, 2012). Likuiditas yang tersedia pada bank syariah harus berada pada kecukupan yang stabil, tidak boleh berada terlalu tinggi atau terlalu rendah, karena ketidakstabilan tersebut akan mengganggu pada pemenuhan kebutuhan operasional dan menurunkan efisiensi sehingga berdampak pada profitabilitas. berikut:

Berdasarkan Surat Edaran, kriteria kesehatan bank dari sisi FDR dilihat berdasarkan kriteria

Tabel 3 Matriks Kriteria Penetapan Peringkat FDR

\begin{tabular}{|c|c|c|}
\hline Peringkat & Tingkat keadaan & Kriteria \\
\hline 1 & Sangat Sehat & FDR $<75 \%$ \\
\hline 2 & Sehat & $75 \% \leq$ FDR $<85 \%$ \\
\hline
\end{tabular}


Health Level Analysis Of PT. Bank Rakyat Indonesia (BRI) Syariah...

\begin{tabular}{|c|c|c|}
\hline 3 & Cukup sehat & $85 \% \leq$ FDR $<100 \%$ \\
\hline 4 & Kurang Sehat & $100 \% \leq$ FDR $<120 \%$ \\
\hline 5 & Tidak Sehat & FDR $\geq 120 \%$ \\
\hline
\end{tabular}

Sumber: Surat Bank Indonesia

Adapun data kondisi FDR Bank pada tahun 2018 sampai dengan 2019 pada tabel berikut:

Tabel 4 Kondisi Financing to Deposit Ratio (FDR)

\begin{tabular}{|l|l|l|l|l|l|}
\hline No & Nama & 2018 & Nilai & 2019 & Nilai \\
\hline 1 & PT. BRI Syariah & $75,49 \%$ & Sehat & $80,12 \%$ & Sehat \\
\hline 2 & PT. BNI Syariah & 79,62 & Sehat & $74,31 \%$ & Sangat Sehat \\
\hline 3 & PT. BSM & 74,89 & Sangat Sehat & 75,54 & Sehat \\
\hline
\end{tabular}

Sumber: Annual Report PT. BRI Syariah, PT. BNI Syariah, dan PT. BSM 2019

Berdasarkan laporan keuangan setiap bank umum syariah milik BUMN, dapat dilihat bahwa kondisi kesehatan bank umum syariah masih berada pada kriteria sehat dan sangat sehat. Hal ini menunjukkan tingkat FDR bank umum syariah milik BUMN berada pada level sesuai dengan standar BI. Dimana artinya bank umum syariah milik BUMN mampu menyalurkan pembiayaan dengan efektif dan likuiditas yang dimilikinya sangat bagus karena mampu memenuhi kebutuhan operasional dan dapat menjaga stabilitas profitabilitas. BRI Syariah tahun 2018 dan 2019 memiliki tingkat kesehatan FDR yang berada pada ketegori sehat, walaupun pada tahun 2019 rasionya meningkat. Menurut peneliti, BRI Syariah harus mengendalikan rasio FDR nya karena, tingginya rasio FDR menunjukkan kurangnya dana likuid pada bank tersebut. Unutk mengendalikannya, BRI Syariah dapat melakukan screening priority terhadap pengajuann pembiayaan yang prioritas dan layak diberikan, selain itu dapat juga dengan meningkatkan dan pihak ketiga agar semakin banyak dana likuid yang tersedia.

\subsection{Analisis Tingkat Kesehatan Return On Assets (ROA)}

Guna mengukur keberhasilan menajamen bank syariah dalam menghasilkan laba menggunakan total aset yang tersedia dapat dilihat melalui persentase Tingkat Pengembalian Aset atau ROA yang dimiliki oleh bank syariah tersebut. Apabila ROA yang pada bank tersebut semakin rendah maka hal tersebut menunjukkan bank tidak mampu mengefisiensikan total asetnya untuk meningkatkan pendapatan bank dan menekan pengeluaran beban (Rustam, 2013).

Berdasarkan Surat Edaran kriteria untuk menilai kesehatan bank umum melalui ROA dapat dilihat pada matriks kriteria berikut ini:

Tabel 5 Matriks Kriteria Penetapan Peringkat ROA

\begin{tabular}{|c|c|c|}
\hline Peringkat & Tingkat keadaan & Kriteria \\
\hline 1 & Sangat Sehat & ROA $>1,50 \%$ \\
\hline 2 & Sehat & $1,25<\mathrm{ROA} \leq 1,50 \%$ \\
\hline 3 & Cukup sehat & $0,5 \%<\mathrm{ROA} \leq 1,25 \%$ \\
\hline 4 & Kurang Sehat & $0 \%<\mathrm{ROA} \leq 0,5 \%$ \\
\hline 5 & Tidak Sehat & $\mathrm{ROA} \leq 0 \%$ \\
\hline
\end{tabular}

Sumber: Surat Bank Indonesia 
Adapun data kondisi ROA Bank Umum Syariah pada tahun 2018 sampai dengan 2019 dapat dilihat dari tabel berikut:

Tabel 6 Kondisi Return On Assets (ROA)

\begin{tabular}{|c|l|l|l|l|l|}
\hline No & Nama & 2018 & Nilai & 2019 & Nilai \\
\hline 1 & PT. BRI Syariah & $0,43 \%$ & Kurang Sehat & $0,31 \%$ & Kurang Sehat \\
\hline 2 & PT. BNI Syariah & $1,42 \%$ & Sehat & $1,82 \%$ & Sangat Sehat \\
\hline 3 & PT. BSM & $0,88 \%$ & Cukup Sehat & $1,69 \%$ & Sangat Sehat \\
\hline
\end{tabular}

Sumber: Annual Report PT. BRI Syariah, PT. BNI Syariah, dan PT. BSM 2019

Merujuk pada data di atas, menurut hemat peneliti PT. BRI Syariah masih harus meningkatkan nilai ROA nya karena dua tahun berturut-turut memiliki ROA dengan kriteria kurang sehat. Sedangkan PT. BNI Syariah memiliki kondisi ROA yang sehat dan meningkat menjadi kriteria peringkat satu pada tahun 2019, hal ini berarti BNI Syariah berhasil mengelola asetnya dalam menghasilkan pendapatan dan laba yang tinggi. Sementara PT. BSM memiliki ROA yang cukup sehat pada 2018 dan meningkat persentasenya sehingga juga berada pada kategori sangat sehat walau angkanya masih di bawah PT. BNI Syariah. Melihat hal tersebut, dari sisi ROA tingkat kesehatan bank umum syariah milik BUMN masih diungguli oleh BNI Syariah, sehingga dua bank lainnya masih harus bekerja keras meningkatkan ROA nya. Untuk meningkatkan ROA, bank dapat mengendalikan pengeluaran BOPO nya dan menurunkan rasio pembiayaan bermasalahnya serta meningkatkan Dana Pihak Ketiga.

\subsection{Analisis Tingkat Kesehatan Beban Operasional terhadap Pendapatan Operasional (BOPO)}

Kemampuan bank dalam pelaksanaan operasional dan pengukuran keefisiensian pendapatan terhadap beban operasional disebut rasio BOPO. BOPO yang rendah mengindikasikan bahwa bank semakin efisien dalam menekan beban operasionalnya (Rivai \& Ismail, 2013). Berdasarkan PBI, tingkat kesehatan BOPO dapat dilihat melalui kriteria di bawah ini:

Tabel 7 Matriks Kriteria Penetapan Peringkat BOPO

\begin{tabular}{|c|c|c|}
\hline Peringkat & Tingkat keadaan & Kriteria \\
\hline 1 & Sangat Sehat & $<94 \%$ \\
\hline 2 & Sehat & $94 \%-95 \%$ \\
\hline 3 & Cukup sehat & $95 \%-96 \%$ \\
\hline 4 & Kurang Sehat & $96 \%-97 \%$ \\
\hline 5 & Tidak Sehat & $>97 \%$ \\
\hline
\end{tabular}

Sumber: Surat Bank Indonesia

Adapun data kondisi BOPO Bank BRI Syariah pada tahun 2018 sampai dengan 2019 tabel berikut: 
Tabel 8 Kondisi BOPO

\begin{tabular}{|c|l|l|l|l|l|}
\hline No & Nama & 2018 & Nilai & 2019 & Nilai \\
\hline 1 & PT. BRI Syariah & $95,32 \%$ & Cukup Sehat & $96,80 \%$ & Kurang Sehat \\
\hline 2 & PT. BNI Syariah & $85,37 \%$ & Sangat Sehat & $81,26 \%$ & Sangat Sehat \\
\hline 3 & PT. BSM & $91,16 \%$ & Sangat Sehat & $82,89 \%$ & Sangat Sehat \\
\hline
\end{tabular}

Sumber: Annual Report PT. BRI Syariah, PT. BNI Syariah, dan PT. BSM 2019

Merujuk pada data yang terdapat pada laporan keuangan yang telah dipublikasikan, BRI Syariah memiliki BOPO yang relatif tinggi sehingga mengindikasikan kesehatan banknya dari segi BOPO kurang sehat pada 2019 dan cukup sehat pada 2018. BRI Syariah harus mengendalikan Beban Operasional yang dikeluarkan agar bisa menjaga kesehatan pendapatan operasionalnya. BNI Syariah dan BSM menjadi bank umum syariah milik BUMN yang memiliki pengendalian baik atas beban operasionalnya, sehingga bisa dilihat pada ROA nya yang juga berada pada kriteria sangat sehat. Tingginya nilai BOPO BRI Syariah ini karena penurunan nilai aset keuangan. Pengendalian BOPO dapat dilakukan dengan menurunkan cadangan kerugian pembiayaan dan untuk memitigasi risiko penyaluran pembiyaan harus tepat sasaran agar tidak terjadi pembiayaan bermasalah. Selain itu, BRI syariah harus meningkatkan skala usahanya.

\subsection{Analisis Tingkat Kesehatan Capital Adequancy Ratio (CAR)}

Guna mengukur seberapa besar kecukupan modal yang dimiliki bank untuk mendukung aset yang menghasilkan risiko, bank menggunakan rasio CAR. Cara menghitung CAR dengan membandingkan antara Modal Bank dengan Aktiva Tertimbang Menurut Risiko (ATMR). (Maramis, 2020). Berdasarkan PBI, penilaian CAR dilihat melalui matriks kriteria berikut ini:

Tabel 9 Matriks Kriteria Penetapan Peringkat CAR

\begin{tabular}{|c|c|c|}
\hline Peringkat & Tingkat keadaan & Kriteria \\
\hline 1 & Sangat Sehat & $<94 \%$ \\
\hline 2 & Sehat & $94 \%-95 \%$ \\
\hline 3 & Cukup sehat & $95 \%-96 \%$ \\
\hline 4 & Kurang Sehat & $96 \%-97 \%$ \\
\hline 5 & Tidak Sehat & $>97 \%$ \\
\hline
\end{tabular}

Sumber: Surat Bank Indonesia

Adapun data kondisi CAR Bank pada tahun 2018 sampai dengan 2019 tabel berikut:

\section{Tabel 10 Kondisi CAR}

\begin{tabular}{|c|l|l|l|l|l|}
\hline No & Nama & 2018 & Nilai & 2019 & Nilai \\
\hline 1 & PT. BRI Syariah & $29,73 \%$ & Sangat Sehat & $25,26 \%$ & Sangat Sehat \\
\hline 2 & PT. BNI Syariah & $19,31 \%$ & Sangat Sehat & $18,88 \%$ & Sangat Sehat \\
\hline 3 & PT. BSM & 16,26 & Sangat Sehat & $16,15 \%$ & Sangat Sehat \\
\hline
\end{tabular}

Sumber: Annual Report PT. BRI Syariah, PT. BNI Syariah, dan PT. BSM 2019

Dengan hasil seperti tabel di atas, peneliti menarik kesimpulan bahwa Bank Umum Syariah milik BUMN memiliki rasio kecukupan modal yang sangat baik atas seluruh hutang yang 
dimiliki oleh ketiga bank tersebut. Maka, peneliti berpendapat bahwa dengan kondisi objektif seperti di atas, agar bank umum syariah milik BUMN mempertahankan CAR yang dimiliki karena mengingat keadaan ekonomi Indonesia yang tidak stabil akan mengguncang keuntungan yang didapatkan oleh ketiga bank. Rendahnya nilai CAR ini mengindikasikan kuatnya permodalan bank syariah, yang disebabkan oleh pembiayaan tumbuh dengan baik dan diikuti dengan kualitas pembiayaan yang juga tergolong baik. Selain itu, tiga bank syariah milik BUMN tersebut konsisten memperkuat anak usaha syariahnya.

\subsection{Analisis Tingkat Kesehatan Return On Eqity (ROE)}

Return On Equity (ROE) menjadi rasio yang digunakan untuk melihat kemampuan bank mendapatkan net profit setelah pajak dari modal yang telah diberikan oleh investor. Semakin besar rasio ini, mengindikasikan bank mampu mengelola modal dengan baik sehingga menghasilkan laba bersih yang tinggi. Berdasarkan peraturan BI, untuk melihat tingkat kesehatan bank dari segi ROE dapat dilihat melalui tabel di bawah ini:

Tabel 11 Matriks Kriteria Penilaian Tingkat Kesehatan ROE

\begin{tabular}{|c|c|c|}
\hline Peringkat & Tingkat keadaan & Kriteria \\
\hline 1 & Sangat Sehat & $>20 \%$ \\
\hline 2 & Sehat & $12,5 \%-20 \%$ \\
\hline 3 & Cukup sehat & $5,01 \%-12,5 \%$ \\
\hline 4 & Kurang Sehat & $0 \%-5 \%$ \\
\hline 5 & Tidak Sehat & $>0 \%$ \\
\hline
\end{tabular}

Adapun data kondisi ROE Bank BRI Syariah pada tahun 2018 sampai dengan 2019 dapat dilihat dari tabel berikut

Tabel 12 Kondisi ROE

\begin{tabular}{|c|l|l|l|l|l|}
\hline No & Nama & 2018 & Nilai & 2019 & Nilai \\
\hline 1 & PT. BRI Syariah & $2,49 \%$ & Kurang Sehat & $1,57 \%$ & Kurang Sehat \\
\hline 2 & PT. BNI Syariah & $10,53 \%$ & Cukup Sehat & $13,54 \%$ & Sehat \\
\hline 3 & PT. BSM & $8,21 \%$ & Cukup Sehat & $15,66 \%$ & Sehat \\
\hline
\end{tabular}

Sumber: Annual Report PT. BRI Syariah, PT. BNI Syariah, dan PT. BSM 2019

Merujuk pada informasi di atas, menurut analisis peneliti PT. BRI Syariah mempunyai persentase ROE yang kurang sehat. Hasil ini berada dibawah BNI Syariah dan BSM yang memiliki ROE pada peringkat sehat. Hal ini mengindikasikan bahwa BRI Syariah tidak mampu mengembalikan secara maksimal modal yang ditanamkan melalui dividen. Karena modal tersebut tidak berputar secara optimal sehingga membuat posisi ROE kurang sehat.

Penelitian ini mengantarkan peneliti pada temuan bahwa tingkat kesehatan PT. BRI Syariah masih dibawah dua bank umum syariah milik BUMN lainnya yaitu BNI Syariah dan BSM. Maka, menurut hemat peneliti manajemen BRI Syariah harus melakukan perbaikan pengelolaan dan kebijakan untuk meningkatkan kesehatan banknya. Karena jika tahun ini dan beberapa tahun ke depan tingkat kesehatan BRI Syariah tidak berada pada peringkat sangat sehat dari 
segala faktor, maka akan sulit bertahan bagi BRI Syariah di era pandemi Covid-19 ini karena aset, dana pihak ketiga, dan laba yang turun. Selain itu pembiayaan bermasalah juga meningkat sehingga berdampak langsung pada pendapatan dan laba. Oleh karena itu, kebijakan BRI Syariah harus dievaluasi kembali untuk menyusun rencana peningkatan kesehatan bank syariah.

\section{Kesimpulan}

Penelitian ini menghasilkan kesimpulan bahwa tingkat kesehatan PT. Bank Rakyat Indonesia (BRI) Syariah jika dibandingkan dengan bank umum syariah milik BUMN lainnya masih harus ditingkatkan lagi. Dari segi NPF BRI syariah memiliki tingkat kesehatan pada peringkat dua yaitu sehat, peringkat ini berada dibawah dua bank umum syariah milik BUMN lainnya. Kemudian dari segi FDR, tingkat kesehatan BRI Syariah berada pada peringkat dua yaitu sehat. Hasil tersebut seimbang dengan dua bank BUMN lainnya. Selanjutnya dari segi ROA, BRI Syariah memiliki kondisi ROA yang kurang sehat, hal ini tentu berada di bawah bank umum syariah milik BUMN lainnya. Sementara dilihat dari segi BOPO, kriteria kesehatanya berada pada kategori cukup sehat dan kurang sehat, hasil ini juga dibawah dua bank umum syariah milik BUMN lainnya. Lalu, dari segi CAR. BRI Syariah memiliki rasio kecukupan modal yang efisien dan sama dengan dua bank umum syariah lainnya. Dan terakhir, tingkat kesehatan BRI Syariah dari segi ROE masih jauh berada di bawah BNI Syariah dan BSM, karena berada pada kriteria tiga yaitu kurang sehat.

\section{Referensi}

Editor. (2011, Oktober 25). Peraturan Bank Indonesia Nomor 13/1/PBI/2011. Dipetik Oktober 15, 2020, dari https://www.bi.go.id/id/peraturan/perbankan/Documents/828aa23594154a89aeabab7 dc3103805pbi_130112.pdf.

Editor. (2020). Laporan Tahunan Bank Syariah Mandiri. Dipetik Oktober 17, 2020, dari https://www.mandirisyariah.co.id/tentang-kami/company-report/annual-report

Editor. (2020). Laporan Tahunan BNI Syariah. Dipetik Oktober 17, 2020, dari https://www.bnisyariah.co.id/enus/company/investorrelation/presentationreport/annualreport.

Editor. (2020, Februari 5). Laporan Tabunan BRI Syariah. Dipetik Oktober 17, 2020, dari https://www.brisyariah.co.id/tentang_hubInvestor.php?f=annual

Maramis, P. A. (2020). Analisis Tingkat Kesehatan Bank dengan Metode RGEC pada PT. Bank Mandiri (Persero) Periode 2015-2018. Jurnal Pembangunan Ekonomi dan Keuangan Daerah, $1-32$.

Pratiwi, D. D. (2012). Pengarub CAR, BOPO, NPF, dan FDR terhadap ROA Bank Umum Syariah di Indonesia. Semarang: Universitas Diponegoro.

Rivai, V., \& Ismail, R. (2013). Islamic Risk Management for Islamic Bank . Jakarta: Gramedia Pustaka Utama.

Rustam, B. R. (2013). Manajemen Risiko Perbankan . Jakarta: Salemba Empat.

Sugiyono. (2013). Metode Penelitian Kuantitatif Kualitatif dan R \&D . Bandung: Alfabeta.

Umam, K. (2013). Manajemen Perbankan Syariah . Bandung: Pustaka Setia. 